\title{
Meningkatkan Keaktifan dan Hasil Belajar Matematika Dengan Implementasi Media Geogebra Pada Siswa SMA
}

\author{
Surya Mayadi \\ email: suryamayadi9@gmail.com \\ SMA Negeri 1 Selong
}

Received: Oktober 2020
Accepted: Juni 2021

Online Published: Juli 2021

\begin{abstract}
This study aims to increase the activeness and mathematics learning outcomes of students through the implementation of Geogebra learning media. This type of research is the PTK (Classroom Action Research). The subjects receiving the action were class X MIPA 3 students of SMA Negeri 1 Selong in the 2019/2020 school year, totaling 36 students. The data collection method used is the method of documentation, observation and test methods. The data analysis technique used is the process of data analysis, data presentation, and data verification. The results showed an increase in student activeness and learning achievement in the Trigonometric Function Graph material. This can be seen from: 1) There was an increase in the average student learning activeness from 58.8 in the initial state to 63.4. In other words, there was an increase from medium criteria to high criteria. 2) There is an increase in the average student achievement from 67 in the initial state to 76 in the first cycle and to 81 in the second cycle. Likewise, the percentage of students who reached the KKM from $44.4 \%$ in the initial conditions, to $63.9 \%$ in the first cycle and an increase of $80.6 \%$ in the second cycle.
\end{abstract}

\section{Keywords : activity, Learning outcomes, GeoGebra}

\begin{abstract}
Abstrak
Penelitian ini bertujuan untuk meningkatkan keaktifan dan hasil belajar matematika siswa melalui implementasi media pembelajaran Geogebra. Jenis penelitian ini adalah PTK (Penelitian Tindakan Kelas). Subyek penerima tindakan adalah siswa kelas X MIPA 3 SMA Negeri 1 Selong tahun ajaran 2019/2020 yang berjumlah 36 siswa. Metode pengumpulan data yang digunakan adalah metode dokumentasi, observasi dan metode tes. Teknik analisis data yang digunakan adalah proses analisis data, penyajian data, dan verifikasi data. Hasil penelitian menunjukkan adanya peningkatan keaktifan dan prestasi belajar siswa pada materi Grafik Fungsi Trigonometri. Hal ini dapat dilihat dari: 1) Adanya peningkatan rata - rata keaktifan belajar siswa dari 58,8 pada keadaan awal menjadi 63,4. Dengan kata lain terjadi peningkatan dari kriteria sedang menjadi kriteria tinggi. 2) Adanya peningkatan rata - rata prestasi belajar siswa dari 67 pada keadaan awal menjadi 76 pada siklus I dan menjadi 81 pada siklus II. Demikian juga persentase siswa yang mencapai KKM dari $44.4 \%$ pada kondisi awal, menjadi $63,9 \%$ pada siklus I dan naik $80,6 \%$ pada siklus II.
\end{abstract}

Kata kunci : Keaktifan, Prestasi Belajar, GeoGebra

\section{PENDAHULUAN}

Revolusi Industri 4.0 adalah sebuah tantangan dalam seluruh bidang ilmu, termasuk dalam bidang pendidikan. Bagi guru dituntut beradapatasi dengan cepat dengan memahami 


\section{Educatio: Jurnal IImu Kependidikan}

Vol. 16, No 1 Juli 2021, hal. 1-8

http://e-journal.hamzanwadi.ac.id/index.php/edc

e-ISSN: $2527-9998$

DOI: 10.29408/edc.v16i1.2691

teknologi dan informasi serta cara mengimplementasikannya. Dampak positif langsungnya adalah guru justru memperoleh lebih banyak referensi dan metode pengajaran. Muara akhir yang didapat seharusnya adalah peningkatan mutu pendidikan.

Upaya untuk meningkatkan mutu pendidikan diantaranya adalah menciptakan suasana belajar yang menarik dan menyenangkan di dalam kelas termasuk menciptakan inovasi media pembelajaran. Perlunya melakukan inovasi dalam media pembelajaran untuk dapat meningkatkan minat, motivasi maupun hasil belajar siswa. Menurut Arsyad (2015: 16), media pembelajaran termasuk alat untuk melakukan evaluasi pembelajaran sehingga dapat membantu siswa meningkatkan motivasi, minat belajar siswa, serta meningkatkan pemahaman, juga mampu menyajikan data dengan menarik, terpercaya, dan memadatkan informasi. Pemanfaatan media pembelajaran menjadi bagian yang wajib mendapat perhatian pendidik (guru) dalam proses pembelajaran. Berdasarkan hal tersebut guru perlu mempelajari dan memahami bagaimana memilih media pembelajaran yang tepat untuk dirapkan agar tujuan pembelajaran dapat dimaksimalkan tercapai/terpenuhi.

Matematika memegang peranan penting dalam perkembangan sains dan teknologi. Dengan belajar matematika manusia memiliki pengetahuan serta keterampilan dalam mengekspolorasi, memprediksi dan berfikir secara logis dalam memecahkan suatu masalah (Kuswanto, 2020). Salah satu ciri dari matematika yaitu mempunyai sifat objek yang abstrak. Sifat abstrak tersebut menyebabkan banyak siswa yang mengalami kesulitan dalam memahami matematika, sehingga dalam membelajarkan matematika perlu memanfaatkan media pembelajaran untuk mencapai keefektifitasan pembelajaran.

Saat ini telah banyak digunakan software matematika untuk menunjang keefektifan pembelajaran matematika diantaranya adalah Geogebra. Geogebra merupakan aplikasi yang dapat dimanfaatkan untuk menyajikan, menggambarkan dan mendapatkan suatu konsepkonsep matematika. Selain itu penggunaan GeoGebra juga dapat menginterpretasi konsep matematis. Pada materi misalkan Sistem Pertidaksamaan Linier Dua Variabel, Program Linier, Fungsi Kuadrat, Terapan Turunan, Dimensi Tiga, dan seterusnya akan sangat mudah mensimulasikan kondisi-kondisi tertentu dari grafik, luas, jarak terpendek dan seterusnya.

Menurut Hohenwarter (2004), GeoGebra merupakan program komputer (software) untuk memberikan pemahaman tentang matematika, khususnya aljabar dan geometri. GeoGebra memiliki sifat multirepresentasi, yaitu: a) menampilkan aljabar, b) menampilkan grafis, dan c) menampilkan numerik. Penggunaan GeoGebra memiliki tujuan untuk meminimalisir kesulitan siswa yang disebabkan oleh sifat abstrak objek kajian dalam matematika sehingga diharapkan dapat meningkatkan pemahaman konsep matematis siswa.

Trigonometri adalah salah satu materi yang diajarkan disekolah. Materi Trigonometri yang paling awal diberikan untuk siswa SMA jurusan MIPA diberikan di kelas X semester 2 yang meliputi materi: Ukuran Sudut dan Perbandingan Trigonometri, Perbandingan Trigonometri untuk Sudut Berelasi, Identitas Trigonometri, Aturan Sinus, Aturan Cosinus, Luas Segitiga dan Grafik Fungsi Trigonometri. Masalah yang berkaitan dengan grafik fungsi trigonometri terutama, menjadi masalah tersendiri dalam pembelajaran trigonometri. Karena 


\section{Educatio: Jurnal IImu Kependidikan}

Vol. 16, No 1 Juli 2021, hal. 1-8

http://e-journal.hamzanwadi.ac.id/index.php/edc

e-ISSN: 2527-9998

DOI: 10.29408/edc.v16i1.2691

disamping siswa dituntut terampil dalam mengingat nilai trigonometri suatu sudut-sudut, siswa juga dituntut untuk terampil dalam menggambar.

Peneliti mengadakan observasi awal melalui diskusi 1 dengan guru-guru matematika yang mengajar di kelas X di SMAN 1 Selong. Hasil diskusi menunjukkan bahwa prestasi belajar materi Trigonometri masih rendah. Terutama sekali pada sub materi Grafik Fungsi Trigonometri. Hasil diskusi juga menunjukkan bahwa guru tidak pernah menggunakan media pembelajaran GeoGebra dalam membantu pemahaman siswa dalam pembelajaran Grafik Fungsi Trigonometri. Karena pembelajaran matematika dengan bantuan GeoGebra belum digunakan di sekolah, peneliti tertarik untuk melakukan penelitian tersebut dengan tujuan meningkatnya hasil belajar siswa. Oleh karena itu, tujuan penelitian ini adalah meningkatkan Hasil Belajar Matematika siswa dengan Implementasi Media Pembelajaran Geogebra.

\section{METODE PENELITIAN}

Subjek Penelitian Tindakan Kelas (PTK) adalah seluruh kelas X IPA 3 SMA Negeri 1 Selong Tahun Pelajaran 2019/2020 dengan jumlah 36 siswa. Data yang diperoleh dari penelitian ini berupa prestasi belajar dan tingkat keaktifan siswa dalam proses pembelajaran yang mengimplementasikan media GeoGebra. Data-data tersebut diperoleh dengan instrumen pengumpulan data sebagai berikut: a) Test, digunakan untuk memperoleh tes data prestasi belajar siswa. Dasa test ini di ambil pada tiap siklus. Sehingga tiap siklus diperoleh data hasil test materi grafik fungsi trigonometri; b) Observasi, digunakan untuk memperoleh data mengenai keaktifan siswa dalam proses pembelajaran yang mengimplementasikan GeoGebra. Sama seperti hasil belajar, dalam observasi untuk mencari keaktifan belajar siswa diambil dalam setiap siklusnya. Observasi dilakukan oleh observer (teman sejawat) yang sebelumnya telah dilakukan diskusi terkait instrumen pencapaian keaktifan dalam penelitian ini.

Penelitian ini dirancang dalam 2 siklus, yang setiap siklusnya terdiri dari 4 tahapan, yaitu:

1) Perencanaan (Planning); 2) Pelaksanaan (Action); 3) Observasi atau Pengamatan (Observation); 4) Refleksi (Reflektion). Setiap siklus terdiri dari 2 pertemuan tatap muka. Setiap siklus dilaksanakan sesuai dengan perubahan yang ingin dicapai, seperti apa yang telah didesain. Berikut tahapan yang dilakkan pada setiap siklus dalam penelitian ini:

\section{Siklus I}

\section{Perencanaan}

Tahapan ini terdapat beberapa 3nstrum : a) Menentukan tujuan atau kompetensi yang hendak dicapai; b) Menyiapkan media pembelajaran GeoGebra; c) Menentukan tahapan proses pembelajaran dengan menggunakan GeoGebra; d) Merancang perangkat pembelajaran termasuk LKPD ; e) Membuat 3nstrument test untuk tiap-tiap siklus dan lembar observasi siswa yang digunakan pada siklus I dan siklus II; f) Diskusi dengan teman sejawat untuk pelaksanaan observasi pada saat proses penelitian di kelas. 


\section{Educatio: Jurnal IImu Kependidikan}

Vol. 16, No 1 Juli 2021, hal. 1-8

http://e-journal.hamzanwadi.ac.id/index.php/edc

e-ISSN: 2527-9998

DOI: 10.29408/edc.v16i1.2691

\section{Pelaksanaan}

Tahap ini merupakan tahap pelaksanaan implementasi GeoGebra pada proses pembelajaran yang diawali dengan penyampaian tujuan pembelajaran dan materi grafik fungsi trigonometri. Siswa melakukan diskusi kelompok dari LKPD yang diberikan guru. Guru menyampaikan cara penggunaan dan contoh tampilan grafik fungsi trigonometri dengan GeoGebra dan langsung meminta siswa untuk mempraktikkannya untuk memastikan kebenaran grafik yang dibuat hasil diskusi siswa dalam LKPD.

Beberapa contoh tampilan GeoGebra dalam menggambar grafik Fungsi Trigonometri sebagai berikut:

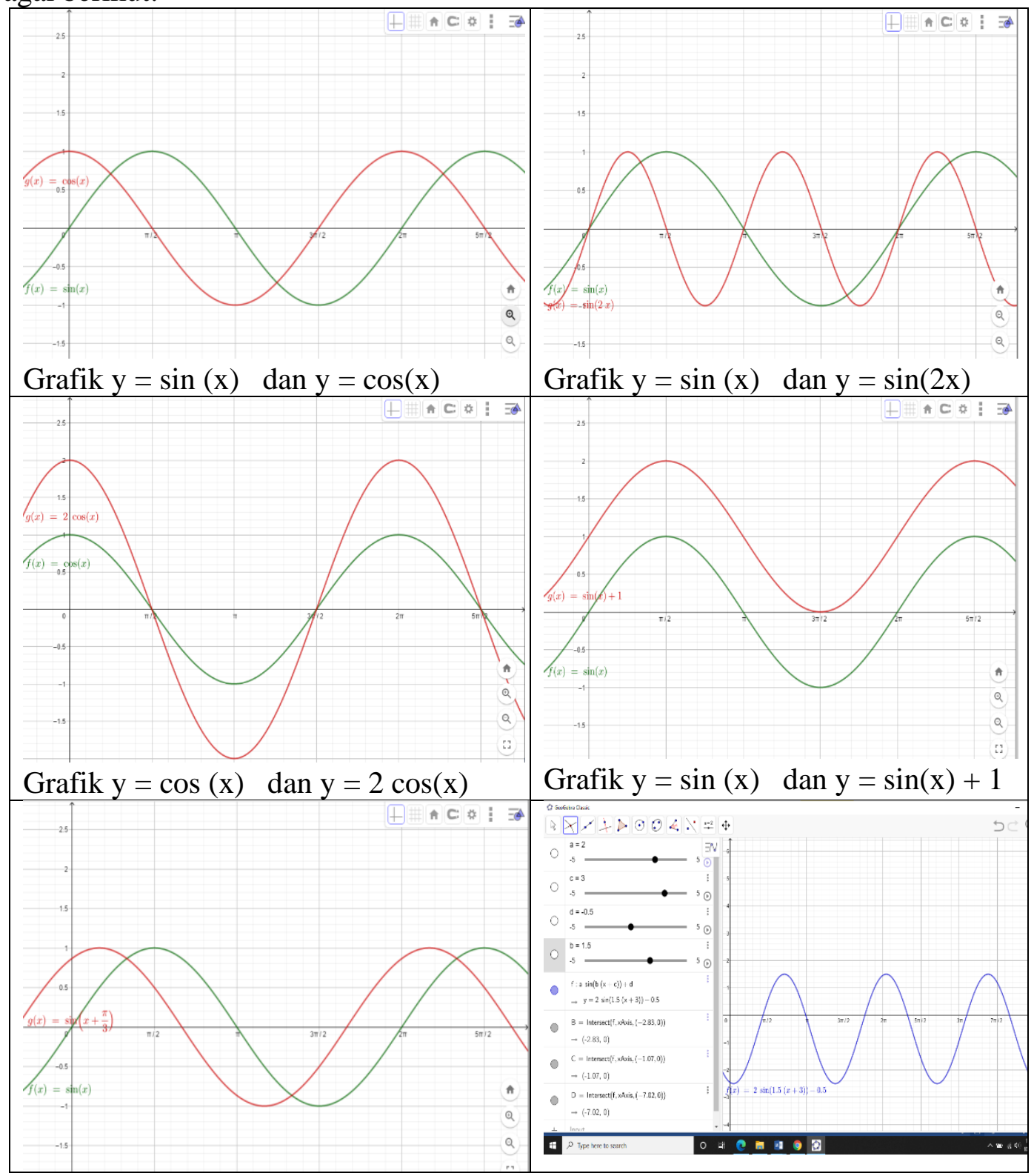




\begin{tabular}{|l|l|} 
Grafik $y=\sin (x)$ dan $y=\sin (x+\pi / 3)$ & $\begin{array}{l}\text { Grafik } y=\cos (x) \text { dan } y=1.5 \cos (x \\
-\pi / 2)+0.5\end{array}$ \\
\hline
\end{tabular}

Gambar 1 Beberapa Contoh Tampilan GeoGebra

3. Observasi atau Pengamatan

Proses observasi dilakukan oleh guru dan observer untuk memperoleh informasi mengenai keaktifan siswa. Guru beserta pengamat, mengamati keaktifan setiap siswa dalam pembelajaran dan memberika penilaian langsung pada lembar observasi keaktifan siswa. Disamping itu dilakukan pencatatan kejadian-kejadian penting pada setiap kegiatan yang dilakukan siswa dimulai dari awal pelajaran hingga akhir pelajaran termasuk masalah efektifitas penggunaan waktu untuk setiap langkah pembelajaran.

4. Refleksi

Secara bersama guru dan pengamat menganalisis hasil pengamatan serta hasil tes. Selanjutnya membuat suatu refleksi, membuat simpulan sementara terhadap pelaksanaan siklus 1. Hasil refleksi digunakan untuk perbaikan tindakan untuk siklus 2.

\section{Siklus II}

Tahapan pelaksanaan Siklus II sama dengan tahapan pelaksanaan pada siklus I. Hasil refleksi pada siklus I dijadikan sebagai dasar perbaikan untuk pelaksanaan siklus II.

\section{HASIL DAN PEMBAHASAN}

\section{a. Tingkat keaktifan}

Hasil tingkat keaktifan siswa dalam pembelajaran terangkum dalam Tabel, Diagram Batang dan Diagram Garis berikut :

Tabel 1 Keaktifan Siswa dalam Pembelajaran Terangkum

\begin{tabular}{|c|c|c|c|c|}
\hline $\begin{array}{c}\text { TINGKAT } \\
\text { KEAKTIFAN }\end{array}$ & Minimum & Maksimum & Rata-rata & Tingkat \\
\hline Siklus I & 50 & 80 & 58,8 & Sedang \\
\hline Siklus II & 52 & 88 & 63,4 & Tinggi \\
\hline
\end{tabular}


Educatio: Jurnal Ilmu Kependidikan

Vol. 16, No 1 Juli 2021, hal. 1-8

http://e-journal.hamzanwadi.ac.id/index.php/edc

e-ISSN: 2527-9998

DOI: 10.29408/edc.v16i1.2691

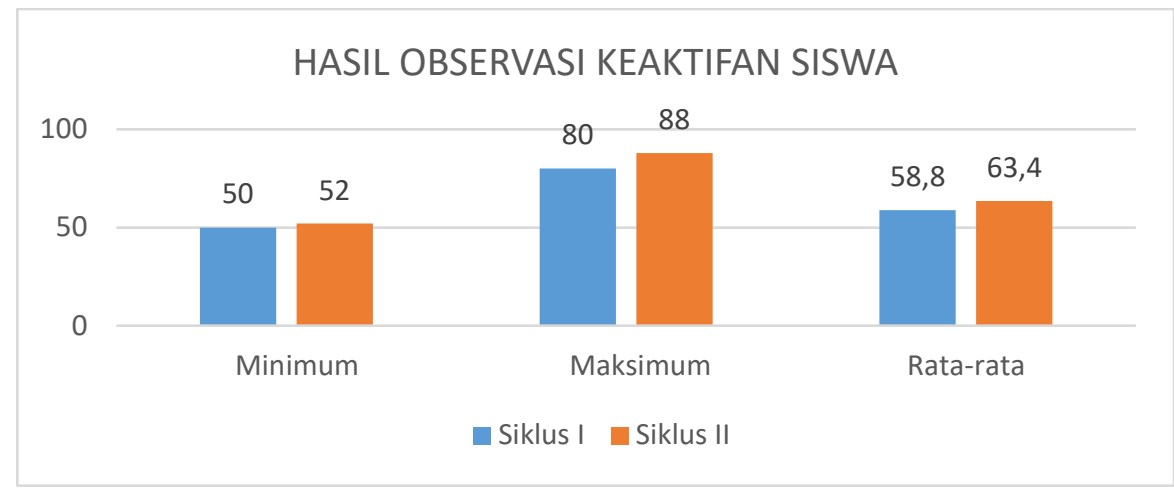

Gambar 2. Diagram Batang Keaktifan Siswa dalam Pembelajaran Terangkum

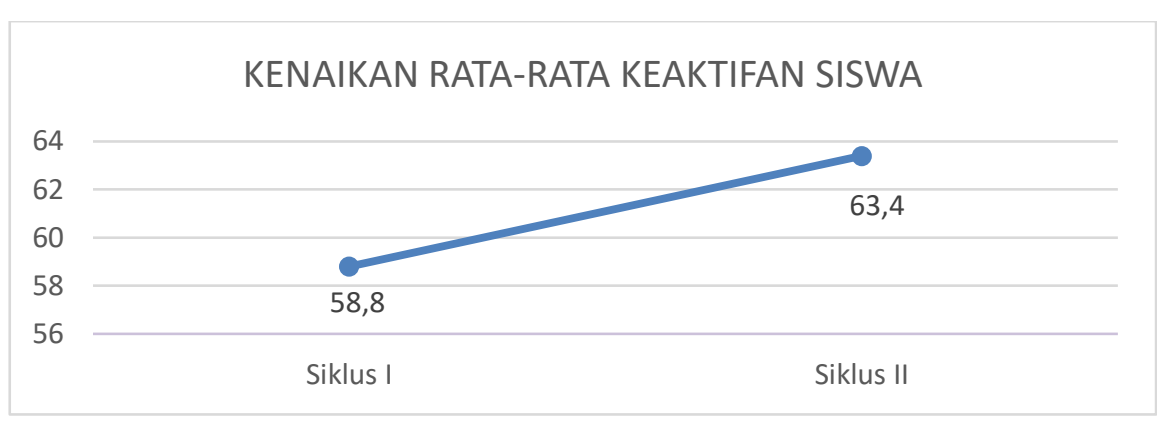

Gambar 3. Diagram Garis Keaktifan Siswa dalam Pembelajaran Terangkum

Berdasarkan hasil pada tabel dan diagram diatas dapat dilihat bahwa terdapat peningkatan keaktifan belajar dari sikulus I ke siklus II. Hal ini ditunjukkan dengan adanya peningkatan rata - rata dari 58,8 pada keadaan awal menjadi 63,4 pada siklus II. Terjadi peningkatan dari kriteria sedang menjadi kriteria tinggi.

\section{b. Prestasi Belajar}

Hasil prestasi belajar siswa dalam pembelajaran terangkum dalam Tabel, Diagram Batang dan Diagram Garis berikut :

Tabel 3. Hasil prestasi belajar siswa dalam pembelajaran terangkum

\begin{tabular}{|r|c|c|c|c|c|}
\hline PRESTASI & Minimum & Maksimum & $\begin{array}{c}\text { Rata- } \\
\text { rata }\end{array}$ & $\begin{array}{c}\text { Jumlah } \\
\text { Siswa } \\
\text { Mencapai } \\
\text { KKM }\end{array}$ & $\begin{array}{c}\text { Persentase } \\
\text { Siswa } \\
\text { Mencapai } \\
\text { KKM }\end{array}$ \\
\hline AWAL & 40 & 86 & 67 & 16 & $44,4 \%$ \\
\hline SIKLUS I & 60 & 90 & 76 & 23 & $63,9 \%$ \\
\hline SIKLUS II & 62 & 94 & 81 & 29 & $80,6 \%$ \\
\hline
\end{tabular}




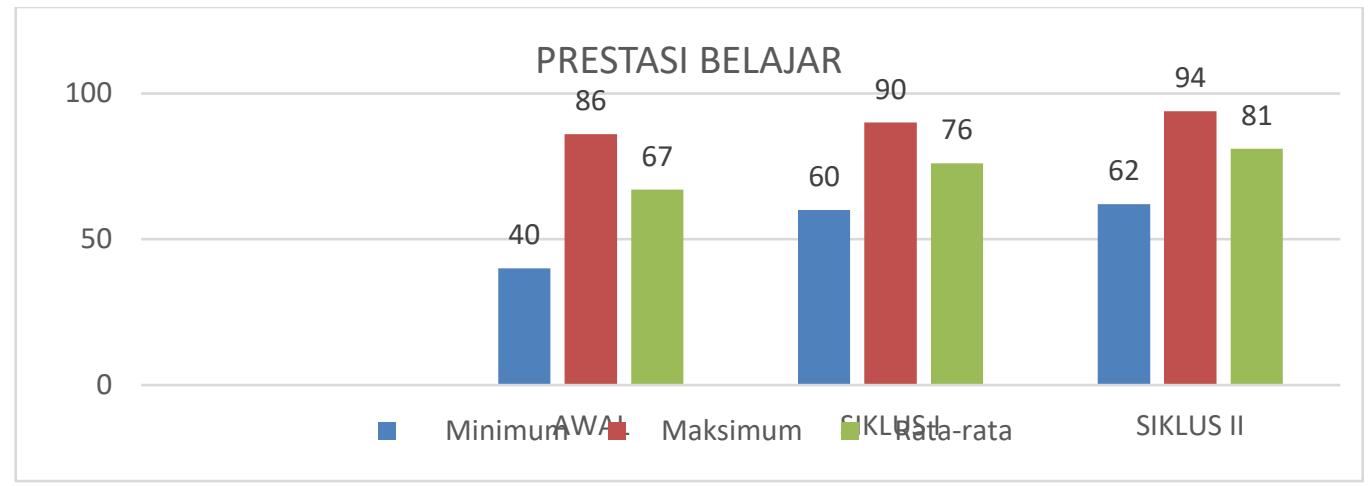

Gambar 4. Diagram Batang Hasil prestasi belajar siswa dalam pembelajaran terangkum

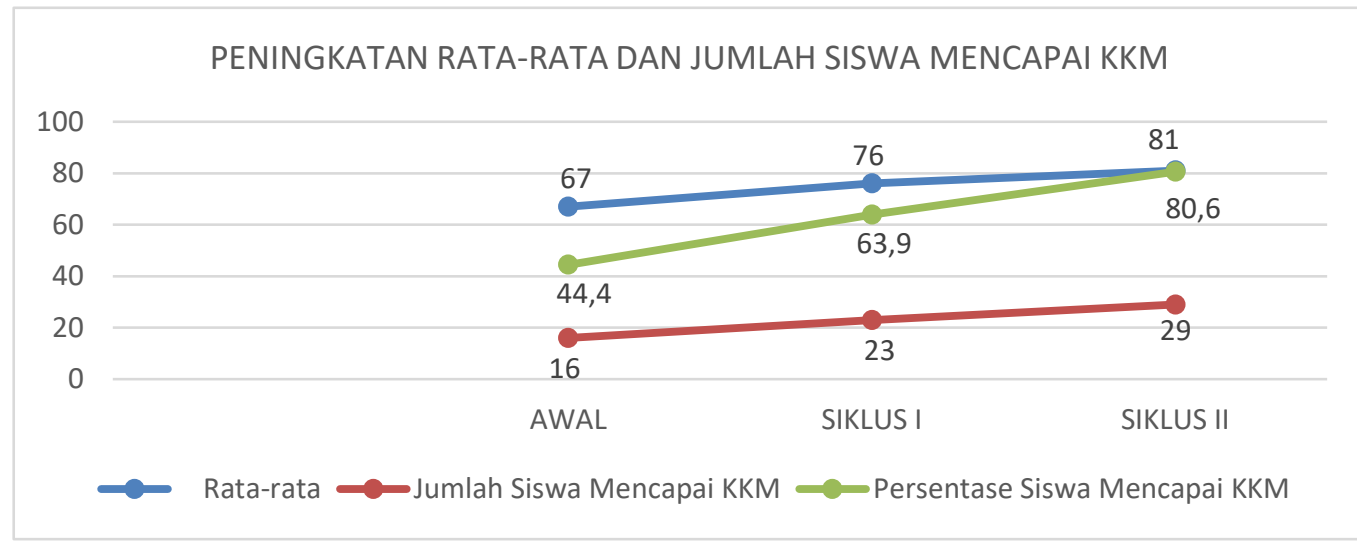

Gambar 5. Diagram Garis Hasil prestasi belajar siswa dalam pembelajaran terangkum

Berdasarkan hasil pada tabel dan diagram diatas dapat dilihat bahwa terdapat peningkatan prestasi belajar dari kondisi awal, sikulus I dan siklus II. Hal ini ditunjukkan dengan adanya peningkatan rata - rata dari 67 pada keadaan awal menjadi 76 pada siklus I dan menjadi 81 pada siklus II. Demikian juga persentase siswa yang mencapai KKM dari 44.4 $\%$ pada kondisi awal, menjadi 63,9 pada siklus I dan naik 80,6 pada siklus II.

\section{SIMPULAN}

Berdasarkan hasil penelitian: Meningkatkan Hasil Belajar Matematika dengan Implementasi Media Pembelajaran Geogebra pada Materi Grafik Fungsi Trigonometri pada Siswa Kelas X MIPA SMA Negeri 1 Selong Tahun Pelajaran 2019/2020 dapat ditarik kesimpulan sebagai berikut : penggunakan media GeoGebra pada pembelajaran grafik fungsi trigonometri dapat meningkatkan keaktifan belajar siswa, dapat meningkatkan prestasi belajar siswa.

\section{PERNYATAAN PENULIS}

Penulis menyatakan bahwa artikel ini belum pernah diterbitkan dalam jurnal manapun. 
Educatio: Jurnal IImu Kependidikan

Vol. 16, No 1 Juli 2021, hal. 1-8

http://e-journal.hamzanwadi.ac.id/index.php/edc

e-ISSN: 2527-9998

DOI: 10.29408/edc.v16i1.2691

\section{DAFTAR PUSTAKA}

Arsyad, A. (2015). Media Pembelajaran. Jakarta: Rajawali Pers

Dimyati dan Mudjiono. (2015). Belajar dan Pembelajaran. Jakarta: Rineka Cipta Henry, S. (2010). Cerdas dengan. Jakarta: PT Gramedia Pustaka Utama

European Journal of Social Sciences Education and Research. 12(1): 211

Hohenwarter, M. \& Fuchs, K. 2004. Combination of Dynamic Geometry, Algebra, and Calculus in the Software System Geogebra. Tersedia: www.geogebra.org/publications/pecs_2004.pdf . Diakses 17 September 2020

Kuswanto, H., Rodiyanti, N., Kholisho, Y. N., \& Arianti, B. D. D. (2020). Pengaruh Kemampuan Matematika Terhadap Kemampuan Computational Thinking Pada Anak Usia Sekolah Dasar. Educatio, 15(2), 138-144.

Mahmudi, A. (2010). Membelajarkan Geometri dengan Program GeoGebra. Makalah disajikan pada Seminar Nasional Matematika dan Pendidikan Matematika. Yogy akarta: Universitas Negeri Yogyakarta.

Mei, S. Y. (2018). Implementing GeoGebra as Based Learning in the Arabic Classroom.

Purba, L. S. L. (2019). Peningkatan Konsentrasi Belajar Mahasiswa Melalui Pemanfaatan Evaluasi Pembelajaran GeoGebra Pada Mata Kuliah Kimia Fisika I. JDP. 12(1) : 29

Puspandari, Dwi. (2012). Pengaruh pembelajaran dalam materi menentukan daerah penyelesaian grafik pertidaksamaan linear menggunakan media pembelajaran Matematika berbasis komputer (Aplikasi Geogebra) terhadap hasil belajar. Jurnal. IAIN Tulungangung 